\title{
Peer Interaction of Children with Hearing Impairment
}

\author{
Xie Yuhan ${ }^{1}$ \\ ${ }^{1}$ Faculty of Education, Sichuan Normal University, Chengdu, China \\ Correspondence: Xie Yuhan, Faculty of Education, Sichuan Normal University, Jing'an Road 5, Jinjiang District, \\ Chengdu, 610068, China. E-mail: yuhanxie2007@163.com
}

Received: August 15, 2013

Accepted: October 9, $2013 \quad$ Online Published: November 5, 2013

doi:10.5539/ijps.v5n4p17

URL: http://dx.doi.org/10.5539/ijps.v5n4p17

\begin{abstract}
Peer interaction servers several crucial functions for all children, with impacting on their communication skills, social adaption, long-term relationships, and the development of cognition, emotion and personality in unique and important ways. As the implement of inclusive education, more and more children with hearing impairment are placed in general schools with typically hearing children. They may face increasing difficulties in interacting and forming positive relationships with peers. In order to provide a completely understanding peer interaction of children with hearing impairment in inclusive educational settings, this article depicts the status of their interaction with peers, the influencing factors and possible intervention programs.
\end{abstract}

Keywords: peer interaction, children with hearing impairment, the status, influencing factors, intervention programs

\section{Introduction}

For young children, building relationships with peers is at the core of development, requiring the skills and knowledge necessary for interacting positively and successfully with peers (Kemple \& Ellis, 2005). Peer interaction is viewed as the social exchange of some duration between/among individuals, which refers to dyadic behaviors in which the participants' actions are interdependent (Rubin, Bukowski \& Parker, 2006), such as communication (non-linguistic and linguistic, positive and negative) and social play with peers (Antia \& Kreimeyer, 2003). Researchers consistently stress the central importance of peer interaction to children's development and well-being. For example, positive peer interactions and relationships in early childhood play a crucial role on the quality of later relationships, social adjustment and successful emotion regulation in the future (Zins , Weissberg, Wang \& Walberg, 2004; McElwain \& Valling, 2005). The ability to interact effectively with peers is also beneficial to the cognitive development and school success (Ladd \& Colemen, 1997).

Unfortunately, for children with developmental delays and related disabilities, there are substantial problems in their abilities to establish relationships and develop friendships with their peers (Guralnick, 2010). The leading researcher in social competence of children with disabilities proposes that developing the abilities to interact with peers should be a primary goal of early intervention and early childhood programs (Guralnick, 2001). In the case of children with hearing impairment, they appears to be neglected by peers (Nunes, Pretzlik \& Olson, 2001) and experience more isolation and loneliness in school than do hearing children (Most, 2007). Therefore, it is important to pay great attention on fostering their positive peer interaction when educating and rehabilitating children with hearing impairment (Dao, 2004).

As the implement of inclusive education, more and more children with hearing impairment are placed in general schools, where they may face increasing difficulties in forming and sustaining positive relationships with their hearing peers in such hearing and oral environment. Their social interaction with peers is becoming a serious concern for educators and parents. In this article, peer interaction of children with hearing impairment in the inclusive settings is depicted from three aspects: the status of their interaction with hearing peers, the influencing factors and possible intervention programs, in order to provide a completely understanding interaction between children with hearing impairment and peers in inclusive education. Hearing impairment used in this article is according to WHO classification, which refers to hearing loss ranging from 'no impairment ( $25 \mathrm{dBHL}$ or less, better ear)' to 'profound impairment including deafness (81dBHL or greater, better ear)' (WHO, 1991). 


\section{The Status of Peer Interaction of Children with Hearing Impairment}

Brown, Remine, Prescott, and Rickards (2000) noted that a three-stage model of social interaction had been developed based on previous studies: (1) surveillance, children spend time surveying the behaviors of others to orient their behaviors to those with whom they wish to interact; (2) entry, children think about and adopt a initiation strategy to gain interaction entry; (3) maintenance, children attempt to maintain their involvement in the social interaction. The behaviors at surveillance and entry stages were regarded to be the initiating interaction strategies by Brown and his colleagues (2000). In this review, peer interaction is considered to include mainly two stages: the first stage of initiating interaction and the second stage of maintaining interaction. This article describes the status of hearing impaired children's peer interaction in the two stages.

\subsection{Initiating Peer Interaction}

Initiating peer interaction is required before an interaction exchange which can be established. It is especially important, because it captures key skills that provide children with access to further socialization opportunities (Cillessen \& Bellmore, 2004). An initiation is defined as any clear and distinct act that is towards to the peer (a peer or peer group) and is not a part of an already existing interaction (Vandell \& George, 1981). Initiation is successful if it elicits a response from the partner and a social interaction occurs. Children with normal hearing often utilize spoken language to initiate a social interaction, for example, calling out the targeted peer's name or say "hello" to the partner. But for the children with hearing impairment, there are difficulties in initiating social interaction by oral language or speech because of their deficiency in hearing and speech. Despite recent advances in promoting spoken language skills, they do not necessarily experience successful interaction with peers (Bat-Chava \& Deignan, 2001).

With reference to the frequency of hearing impaired children's initiation behaviors, some researchers found their initiation interaction as often as their hearing peers in integrated preschools or kindergartens (Brown, Remine, Prescott \& Rickards, 2000). Deluzio and Girolametto (2011) indicated that there were no significant differences in frequency of initiation and ability to respond to others' initiations between children with severe to profound hearing loss and their matched hearing peers. Vandell \& George (1981) even found deaf preschoolers attempted to initiate interactions significantly more than their hearing counterparts.

In terms of initiation strategies used by children, both deaf and hearing preschoolers frequently used vocalizations, smiles, and object-related acts (Vandell \& George, 1981). Successful initiation strategies used by hard-of-hearing children were similar to their hearing classmates, including nonverbal entry, extending an invitation, offering an object, or producing a behavior similar to that in which other children were engaged (Weisel, Most \& Efron, 2005). Additionally, children with hearing impairment could change various initiation strategies according to partner's hearing status. They used more gestural and nonverbal strategies such as "touch" to initiate than did their hearing counterparts in integrated kindergartens (Duncan, 1999). Weisel, Most and Efron (2005) reported that deaf preschoolers preferred to use signing, direct entrance, heading turning in search of a partner when interacting with deaf peers, whereas with hearing peers they more often utilized moving closer, object-related social acts (for instance, pointing or showing an object), and neutral touch. Moreover, they tended to use combined initiation strategies when interacting with deaf peers than they did with hearing peers, especially regarding vocalizations. Children with hearing impairment are probably to be the initiators with inappropriate signals which are impossible to be received, for instance, gestures or vocalizations to one's back (Vandell \& George, 1981). They often wait and hover, use a behavior unrelated to ongoing activity, or disrupt the ongoing play to attempt to join in peer interaction (e.g., an non-play activity), leading to more failure in gaining peer play (Brown, Remine, Prescott \& Rickards, 2000).

Studies got consistent findings that children with hearing impairment experienced greater difficulty in initiating social interactions and their initiation attempts were more likely to be refused or rejected by their hearing partners (Vandell \& George, 1981; Bat-Chava \& Deignan, 2001; Deluzio \& Girolametto, 2011), especially when they attempted to enter a peer group. Knutson et al. (1997) conducted a study with using the peer entry paradigm and found that one third of participants with hearing impairment failed to enter a group situation where a dyad of hearing peers was already interacting. Boyd, Knutson and Dahlstrom (2000) got similar results that $27 \%$ of deaf children failed to enter a peer group of two hearing peers, whereas there were only $5 \%$ of hearing children who failed entry. Additionally, studies manifested that children with impaired hearing had much more difficulty in larger social settings (Bat-Chava \&Deignan, 2001; Martin, Bat-Chaava, Lalwami, \& Waltzman, 2010). Martin, et al. (2010) selected ten 5- to 6-year-old deaf children and six hearing children to investigate their interactions in a Peer Entry task. Deaf participants were assigned to interact with age- and gender-matched hearing children in two levels of difficulty interaction situations: Dyad condition where the deaf child interacted with one hearing 
peer for $30 \mathrm{~min}$, and Triad condition where the deaf child entered a group of two hearing children who had already interacted together for $5 \mathrm{~min}$, and all three children continued to interact for another $25 \mathrm{~min}$. Results revealed that $80 \%$ of the deaf children in the sample experienced some degree of communication breakdown and the deaf children experienced significantly more difficulty in the Triad interaction situation than in the Dyad condition. Their entry failure was more in larger settings $(40 \%$ of deaf children failed entry in the Triad condition, comparing with $20 \%$ in the Dyad condition) and they had less appropriate respond to peers when they joined in an "established" group of hearing peers. The results were line with the finding from Bat-Chava and Deignan (2001) that it was harder for children with hearing impairment to interact with two peers or more than in one-on-one situation.

\subsection{Maintaining Peer Interaction}

Utilizing skilled behaviors to maintain healthy relationships with others is another challenge for children with hearing impairment. Nunes, Pretzlik and Olson (2001) reported that hearing impaired children had more difficulties in making friends and their relationships with peers, and appeared to proceed less smoothly than those of hearing children. Their difficulty in peer relationships might be relevant to their difficulty in maintaining peer interactions which provides opportunities for forming and keeping relationships with peers. Even thought children with hearing impairment have successfully initiated peer interaction, it doesn't ensure they can maintain their involvement in the peer interaction effectively.

Available literatures on maintenance in peer interactions of children with hearing impairment are not sufficient. Deluzio and Girolametto (2011) indicated that there was no significant difference on the mean length of interaction between children with severe to profound hearing loss and children with normal hearing, concluding that the two groups of children did not differ on their ability to maintain interactions with their peers. However, other studies showed that children with hearing impairment had more difficulty in maintaining social interaction than their hearing peers (Antia \& Dittillo, 1998; Duncan, 1999). Antia and Dittillo (1998) observed the social play of children with hearing impairment and hearing children during inside play in small group which was consisted of six to eight children, of whom at least two children were hearing impaired. Thus, the children with hearing impairment had access to both hearing impaired and hearing peers. The researchers found that children with children with hearing impairment engaged in significantly less associative or cooperative play than children with normal hearing: they engaged equally in non-play and social play, while hearing children engaged primarily in social play. In another study conducted by Duncan (1999), 11 children with hearing impaired and 11 hearing children in the preschool and kindergarten were enrolled in the same integrated program. Each child was videotaped during free play and during dyadic interaction with a partner of the opposite hearing status. Results showed that when maintaining interaction, the children with hearing impairment used more minimally contingent responses and made fewer significant contributions than the hearing children.

\section{Influencing Factors}

There are several factors influencing peer interaction of children with hearing impairment. This article focuses on following aspects: the language and speech ability of children with hearing impairment, peer's hearing status and familiarity, communication mode used in interaction and cochlear implants / hearing aids.

\subsection{Language and Speech Ability}

Children with hearing impairment often have some degree of language and/or speech delay, which is a major factor affecting their interaction with hearing peers. Bat-Chava and Deignan (2001) noted that it was the delay in children with hearing impairment language and speech development that created great barriers for them in establishing and sustaining social relationships. In the study by Lederberg (1991), 29 children with hearing impairment were observed during out-door free play with peers. They were divided into high, medium and low language ability levels. Results manifested that children who had high language ability initiated significantly more interactions and spent significantly more time on playing, and also used significantly more linguistic communication with partners than those who had medium or low language ability. Hart, Fujiki, Brinton and Hart (2004) proposed that children with language impairment adapted to their linguistic difficulties by avoiding or withdrawing from interaction, thereby they had limited opportunities to practice interaction skills. Additionally, language and speech impairment is associated with deficits in social cognition or emotional competence that might undermine social interaction. It could be reasonably inferred that because children with hearing impairment generally have poorer language and speech ability than hearing children, their opportunities in interaction with others are not sufficient to learn and practice social skills. Moreover, evidences also showed that children with hearing impairment had deficits in social cognition and emotional competence (Peterson \& Siegal, 2000; Rieffe \& Terwogt, 2006), thus resulting in less success in their interaction with peers. 


\subsection{Peers' Hearing Status and Familiarity}

For peers' hearing status, studies indicated that both children with hearing impairment and hearing children preferred to interact with peers with similar hearing status (Vandell \& George, 1981; Rodriguez \& Lana, 1996). In the study conducted by Vandell and George (1981), dyadic free play of 16 deaf preschoolers and 16 hearing preschoolers were videotaped on 2 occasions (once with hearing partner and once with deaf partner) to assess their peer interaction. Results suggested that mean interaction duration and proportion of time spent in interaction were greater in "like" dyads (hearing child and hearing partner or deaf child and deaf partner) as opposed to "mixed" dyads. Deluzio and Girolametto (2011) reported that hearing playmates initiated interactions less often with the children with severe to profound hearing loss and ignored their initiations more often than those of other hearing children. These results were supported by the former studies, showing that both a higher quantity and quality of social interaction among deaf and hearing children appeared when they knew each other with the same hearing status (Rodriguez \& Lana, 1996; Minnett, Clark \& Wilson, 1994). It is conceivable that children with hearing impairment prefer to interact with peers who are also hearing impaired. Additionally, they use different interaction strategies based on peers' hearing status (Duncan, 1999; Weisel, Most \& Efron, 2005). For example, deaf children use more visual and less object-based strategies when interacting with deaf playmates than interacting with hearing playmates (Lederberg, Ryan \& Robbins, 1986).

For peers' familiarity, researchers argue that familiarity plays a great role in interaction between children with hearing impairment and hearing peers (Lederberg, Ryan \& Robbins, 1986; Kreimeyer, Crooke, Drye, Egbert, \& Klein, 2000; Antia, Reed \& Shaw, 2011). Lederberg, Ryan and Robbins (1986) observed 14 deaf preschool children in dyadic play with familiar and unfamiliar peers. They reported that deaf children had more successful initiations with familiar than with unfamiliar hearing partners. Interestingly, hearing children used more visual communication with a familiar deaf peer than an unfamiliar deaf child. Apparently, hearing and children with hearing impairment who are familiar with one another may find nonlinguistic means of communication to partially overcome language and mode-of-communication barriers (Antia \& Kreimeyer, 2003). Antia, Reed, \& Shaw (2011) stated that the positive effect of peer familiarity could be seen in the co-enrollment program, which was beneficial for social interactions between children with hearing impairment with hearing peers. In the study by Kreimeyer et al. (2000), the social interactions of hearing impaired children who were co-enrolled in the intermediate classrooms were observed. Results manifested that hearing impaired children' interactions with their hearing classmates increased rapidly after the co-enrollment intervention. The co-enrollment program contribute children with hearing impairment to become more and more familiar with their hearing peers through participating together in all classroom activities, thus enhancing peer interaction between them.

\subsection{Communication Mode}

Communication mode used by children with hearing impairment is another influencing variable to the peer interaction. In the inclusive settings, hearing children may not have learned sign language or may have only minimal sign language skills, so oral communication is thought to be key to interaction between children with hearing impairment and hearing peers. Bat-Chava and Deignan (2001) examined the oral language and social relationship of children with hearing impairment with cochlear implants in a general education classroom. Most parents reported that their children's oral communication improved after implant, and they became more willing and able to interact with hearing peers. Conversely, children whose oral communication was not improved after implantation were reported to have difficulties in social relationships with hearing peers. Hulsing et al. (1995) observed the peer interaction of three children with hearing impairment with matched hearing peers in the kindergarten. They found that one child who used oral communication had a similar number of interactions to that of hearing peers, while the other two children who used simultaneous communication had less frequent interactions than hearing children. Other researchers also claimed that children with hearing impairment reported that those who utilized oral were more likely to have interactions with hearing peers than those who used sign. Stinson and Whitmire (1992) investigated self-reported data on the preferred communication mode and social interaction from 64 hearing impaired adolescents. Those adolescents who preferred oral communication reported more interactions with hearing peers than those who preferred sign communication. Similarly, Stinson and Kluwin (1996) found that adolescents who rated themselves low in sign ability reported a preference for interaction with hearing peers. Meanwhile, those who rated themselves high in signing skills reported interacting mostly with other hearing impaired peers.

\subsection{Cochlear Implants/Hearing Aids}

The use of modern hearing technology, such as digital hearing aids and cochlear implants, has provides auditory sensation to individual with hearing impairment, granting them the opportunity to use spoken language as their 
main communication mode in the inclusive educational settings (Lim \& Simser, 2005; Sandgren et al., 2011). Some studies indicated that the social relationships and communication skills of their children with hearing loss were improved as result of cochlear implantation (Bat-Chava \& Deignan, 2001; Bat-Chava, Martin \& Kosciw, 2005; Schorr, 2006). In the study of Bat-Chava, Martin and Kosciw (2005), communication and socialization of children who used hearing aids or cochlear implants for an average of 11 and 6 years were investigated by parents' report. The results found that the socialization skills of children improved over time with the improvement in communication, speech and oral language skills. This finding is line with the result of the previous study that parents reported that cochlear implants had a positive effect on deaf children's ability to interact with hearing peers in a mainstream environment (Bat-Chava \& Deignan, 2001). Schorr (2006) examined the effects of cochlear implants on social and emotion outcomes, focusing on feeling of loneliness in children with hearing loss in general education classes. 37 children with cochlear implants and 37 children with normal hearing, aged from 5 to 14 , participated in this study. The findings demonstrated that children with cochlear implants reported their loneliness were relatively low, and similar to hearing children. An important reason was that children with cochlear implant could speak fluently, which allowed them to interact with hearing classmates and participate classroom activities well, so that they became a true 'member' of the classroom social group. It is worthy to note that cochlear implants only guarantee children could be able to hear environmental sounds (Hyde \& Punch, 2011), but itself cannot allow the social learning and participation of children to proceed without considered support (Punch \& Hyde, 2011).

\section{Intervention Programs}

As children with hearing impairment face difficulties in social interaction, especially with hearing peers, several intervention programs have been developed to improve their ability to interact with peers to promote their social integration in inclusion education.

\subsection{Enhancing Language and Speech Ability Programs}

Early intervention researchers pointed out that early detection and intervention of hearing impaired children's language and speech delays is a critical step and that parents' involving in intervention programs is also very crucial (Moeller, 2000). There are many early intervention programs for language and speech ability, for instance, the Model of Auditory, Speech, and Language Development (Easterbrooks \& Estes, 2007). The Model is designed to assist general and special education teachers in developing spoken language in children with hearing impairment. It emphasizes that teachers should organize the components of listening to spoken language for children with hearing impairment so that they will learn to understand and use them. And a well-prepared, intensely stimulating environment which can foster the natural emergence of listening and spoken language and facilitate language learning would be provided for children with hearing impairment too. Another approach named Auditory-Verbal Therapy is reported to be effective for developing language and speech ability of children with hearing impairment (Lim \& Simser, 2005). The approach is designed to guide the parents of children with hearing impairment to help their children develop audition, speech, language, cognition, and communication skills which are integrated into natural, playful, and age-appropriate activities. It involves individualized, diagnostic sessions emphasizing the use of hearing technology in optimal and meaningful conditions. Researchers indicate that Auditory-Verbal invention has improved hearing impaired children's language and speech ability, as well as their social attention and skills (Wray, Fleser, \& Vaccaro, 1997; Goldberg \& Flexer, 2001).

\subsection{Peer-Mediated Model Programs}

Hearing children prefer to interact with peers who have the same hearing status and may ignore or not willing to respond to the initiation of children with hearing impairment. It is true that children with hearing impairment need greatly the support and scaffolding from their interactional partners. Therefore, instructing normally hearing children interaction strategies may benefit interaction between hearing and children with hearing impairment (Deluzio \& Girolametto, 2011). Peer-mediated interventions emphasize the involvement of typically developing peers as socially competent facilitators to promote appropriate communicative and social behaviors and stress on training typically developing children. It is also important to generate many occasions for practice in order to make the acquired skills permanent and stable over time (Bruce \& Hansson, 2011). According to the approaches organized by DiSalvo and Oswald (2002), there are three main aspects in peer-mediated interventions for children who have difficulty in communication: (1) manipulation of the situation, encouraging typical children to interact with target children, (2) peer instruction in social interaction strategies, teaching typical peer special social skill strategies to enhance social interaction with target children, (3) instruction of targeted child in initiation strategies, teaching them initiation skills to increases peer effectiveness. Researchers 
reported that peer-mediated training was greatly effective to improve communication skills in young children with communication problems (Chung et al. 2007; Bruce \& Hansson, 2011); it might contribute to improve interaction between children hearing impairment and hearing peers.

\subsection{Co-Enrollment Program}

Co-enrollment program could provide students with and without hearing impairment with shared communication means and intensive contact, and increase their familiarity. In the co-enrollment program, students with hearing impairment and typical hearing students are educated together in the same classroom. They are co-taught by a regular education teacher and a special education teacher (Kreimeyer, Crooke, Drye, Egbert, \& Klein, 2000). The number of students with hearing impairment typically ranges from one fourth to one third of the total classroom members. Sign language instruction is integrated into classroom curriculum. All students in the program are involved in all classroom activities and the teacher encourage them to interact with each other by providing ongoing instruction and appropriate communication methods for hearing impaired students and hearing students. The teachers and students in the co-enrollment classrooms frequently use both spoken and sign language, thus allowing communication access for all students (Kreimeyer, Crooke, Drye, Egbert, \& Klein, 2000; Antia, Reed, \& Shaw, 2011). This intervention program has been practiced in education for years, which shows that it has actually positive effect on interaction between hearing and children with hearing impairment in integrated settings (Kreimeyer, Crooke, Drye, Egbert, \& Klein, 2000).

\subsection{Social Skills Training Programs}

In order to improve hearing impaired children's social skills, intervention programs have been developed with aiming at promoting observable positive social skills, or social problem-solving thinking skills, or improving both. For example, the teacher-mediated social skills program which was developed by Antia and Kreimeyer (1994) centers on prompting hearing impaired young children's specific observable positive skills in integrated settings, such as greeting, sharing, assisting, and conversing. Another program developed by Greenberg and Kusche (1993) to increasing deaf children's thinking skills involved in social problem solving, emotional awareness, and behavioral adjustment. However, more programs combine promoting observable positive social skills and thinking skills. For instance, the social competence program developed by Suarez (2000) has been consisted of two parts. The first part is an interpersonal problem-solving training program, including 15 lessons which gradually and progressively developed the cognitive skills needed to avoid or solve interpersonal problems, and is taught to only deaf children in 20 1-hour sessions, twice a week. The second part is a social skills training program including six one-hour sessions and is taught to both deaf children and hearing children. This part is in order for training the social abilities which are selected to be socially valid, including (1) to apologize,(2) to negotiate with peers,(3) to avoid problems with others,(4) to face up to the group influence, and (5) to cooperate and share in group. Suarez (2000) indicated that this invention program succeeded in improving deaf children' social problem-solving skills, especially in making comprehensible the steps implied in the solution of interpersonal problems. This program also improved deaf children's assertive behaviors significantly as rated by their teachers and by themselves.

\section{Conclusion}

According to the studies on peer interaction of children with hearing impairments with peers in inclusive settings, it may be concluded that children with hearing impairment initiate actively and are able to moderate their initiation strategies based on partners' hearing status in interactions; however, they experience more failure in interactions than children with normal hearing, especially when they attempt to initiate and enter an established peer group. Additionally, children with hearing impairment are not adept at maintaining peer interactions as hearing children. The important influencing factors includes language and speech ability of children with hearing impairment, peer's hearing status and familiarity, communication mode used in interaction and cochlear implants / hearing aids. Furthermore, some intervention programs to improve their interaction with peers are put forward, such as enhancing language and speech ability programs, peer-mediated model programs, Co-enrollment program, and social skills training programs. In order to examine these programs of intervention, further practical studies are needed in future.

\section{Reference}

Antia, S. D., \& Dittillo, D. A. (1998). A comparison of the peer social behavior of children who are Deaf/Hard of Hearing and Hearing. Journal of Children's Communication Development, 19, 1-10. http://dx.doi.org/10.1177/152574019801900201 
Antia, S. D., \& Kreimeyer, K. H. (2003). Peer interactions of deaf and hard-of-hearing children. In M. Marschark, \& P. E. Spencer (Eds.). Handbook of deaf studies and deaf education (pp. 164-176). Oxford: OUP.

Antia, S. D., Reed, S., \& Shaw, L. (2011). Risk and resilience for social competence: deaf children in general education classrooms. In D. H. Zand, \& K. J. Pierce (Eds.), Resilience in deaf children: Adaption through emerging adulthood (pp. 65-86). New York: Springer.

Bat-Chava, Y., \& Deignan, E. (2001). Peer relations of children with cochlear implants. Journal of Deaf Studies and Deaf Education, 6, 186-199. http://dx.doi.org/10.1093/deafed/6.3.186

Bat-Chava, Y., Martin, D., \& Kosciw, J. G. (2005). Longitudinal improvements in communication and socialization of deaf children with cochlear implants and hearing aids: Evidence from parental reports. Journal of Psychology and Psychiatry, 46, 1287-1296. http://dx.doi.org/10.1111/j.1469-7610.2005.01426.x

Boyd, R. C., Knutson, J. F., \& Dahlstrom, A. (2000). Social interaction of pediatric cochlear implant recipients with age-matched peers. The Annals of Otology, Rhinology, and Laryngology, 185(Suppl.), 105-109. Retrieved from http://www.highbeam.com/doc/1P3-66759828.html

Brown, P. M., Remine, M. D., Prescott, S. J., \& Rickards, F. W. (2000). Social interactions of preschoolers with and without impaired hearing in integrated kindergarten. Journal of Early Intervention, 23, 200-211. http://dx.doi.org/10.1177/10538151000230030901

Bruce, B., \& Hansson, K. (2011). Promoting peer interaction. Autism Spectrum Disorders-From Genes to Environment, 23, 313-328. $\quad$ Retrieved from http://cdn.intechopen.com/pdfs/19210/InTech-Promoting_peer_interaction.pdf

Chung, K. M., Reavis, S., Mosconi, M., Drewry, J., Matthews, T., \& Tassé, M. J. (2007). Peer-mediated social skills training program for young children with high-functioning autism. Research in Developmental Disabilities, 28, 423-436. http://dx.doi.org/10.1016/j.ridd.2006.05.002

Cillessen, A. H. N., \& Bellmore, A. D. (2004). Social skills and interpersonal perception in early and middle childhood. In P. K. Smith, \& C. H. Hart (Eds.), Blackwell handbook of childhood social development (pp. 355-374). Oxford: Wiley-Blackwell.

Dao, W. (2004). Focus on peer communication among deaf children. Chinese Scientific Journal of Hearing and Speech Rehabilitation, 6, 37-39. http://dx.doi.org/10.3969/j.issn.1672-4933.2004.05.012

Deluzio, J., \& Girolametto, L. (2011). Peer interactions of preschool children with and without hearing loss. Journal of Speech, Language, and Hearing Research, 54, 1197-1210. http://dx.doi.org/10.1044/1092-4388 (2010/10-0099)

DiSalvo, C. A., \& Oswald, D. P. (2002). Peer-mediated interventions to increase the social interaction of children with autism: Consideration of peer expectancies. Focus on Autism and Other Developmental Disabilities, 17, 198-207. http://dx.doi.org/10.1177/10883576020170040201

Duncan, J. (1999). Conversational skills of children with hearing loss and children with normal hearing in an integrated setting. The Volta Review, 101, 193-212. Retrieved from http://lsl.usu.edu/files/Duncan-convers-skills.pdf

Easterbrooks, S. R., \& Estes, E. L. (2007). Helping Deaf and Hard of Hearing children to use Spoken Language: $A$ Guide for Educators and Families. California: Corwin Press.

Goldberg, D., \& Flexer, C. (2001). Auditory-Verbal graduates: Outcome survey of clinical efficacy. Journal of the American Academy of Audiology, 12, 406-414. Retrieved from http://lsl.usu.edu/files/Goldberg-outcome-auditory.pdf

Guralnick, M. J. (2001). A framework for change in early childhood inclusion. In M. J. Guralnick (Ed.), Early childhood inclusion: Focus on change (pp. 3-35). Baltimore: Brookes.

Guralnick, M. J. (2010). Early intervention approaches to enhance the peer-related social competence of young children with developmental delays: A historical perspective. Infants Young Child, 23, 73-83. http://dx.doi.org/10.1097/IYC.0b013e3181d22e14

Greenberg, M. T., \& Kusche, C. A. (1993). Promoting social and emotional development in deaf children. The PATHS Project. Seattle: Unversity of Washington Press. 
Hart, K. I., Fujiki, M., Brinton, B., \& Hart, C. H. (2004). The relationship between social behavior and severity of language impairment. Journal of Speech Language and Hearing Research, 47, 647-662. Retrieved from http://web.ebscohost.com.proxy-ub.rug.nl/ehost/pdfviewer/pdfviewer?vid=7\&sid=650aa33e-6c5c-406d-8cc e-fa4e2f960e $57 \% 40$ sessionmgr113\&hid $=113$

Hulsing, M. M., Luetke-Stahlman, B., Frome-Loeb, D., Nelson, P., \& Wegner, J. (1995). Analysis of successful initiations of three children with hearing loss mainstreamed in kindergarten classrooms. Language, Speech and Hearing Services in the Schools, 26, 45-52. Retrieved from http://web.ebscohost.com.proxy-ub.rug.nl/ehost/pdfviewer/pdfviewer?sid=650aa33e-6c5c-406d-8cce-fa4e2 f960e $57 \% 40$ sessionmgr113\&vid $=6$ \&hid $=113$

Hyde, M., \& Punch, R. (2011). The modes of communication used by children with cochlear implants and role of sign in their lives. American Annals of the Deaf, 155, 535-549. http://dx.doi.org/10.1353/aad.2011.0006

Kemple, K. M., \& Ellis, M. S. (2005). Peer-related social competence in early childhood: supporting interaction and relationships. In E. L. Essa, \& M. M. Burnham (Eds.), Informing our practice: Useful research on young children's development (pp. 5-12). Washington: NAEYC.

Kreimeyer, K. H., Crooke, P., Drye, C., Egbert,V., \& Klein, B. (2000). Academic and social benefits of a co-enrollment model of inclusive education for deaf and hard-of-hearing children. Journal of Deaf Studies and Deaf Education, 5, 174-185. http://dx.doi.org/ 10.1093/deafed/5.2.174

Ladd, G. W., \& Coleman, C. C. (1997). Children's classroom peer relationships and early school attitudes: Concurrent and longitudinal associations. Early Education and Development, 4, 51-66. http://dx.doi.org/10.1207/s15566935eed0801_5

Lederberg, A. R. (1991). Social interaction among deaf preschoolers: The effects of language ability and age. American Annals of the Deaf, 136, 53-59. http://dx.doi.org/0009-3920/81/5202-0008801.00

Lederberg, A. R., Ryan, H. R., \& Robbins, B. (1986). Peer interaction in young deaf children: The effect of partner hearing status and familiarity. Developmental Psychology, 22, 691-700. http://dx.doi.org/10.1037/0012-1649.22.5.691

Lim, S. Y. C., \& Simer, J. (2005). Auditory-Verbal Therapy for children with hearing impairment. Annals Academy of Medicine Singapore, 34, 307-312. http://dx.doi.org/ 10.1002/14651858.CD010100

Martin, D., Bat-Chaava, Y., Lalwami, A., \& Waltzman, S. B. (2010). Peer relationships of deaf children with cochlear implants: predictors of peer entry and peer interaction success. Journal of Deaf Studies and Deaf Education, 16, 108-120. http://dx.doi.org/10.1093/deafed/enq037

McElwain, N. L., \& Volling, B. L. (2005). Preschool children's interactions with friends and older siblings: Relationship specificity and joint contributions to problem behavior. Journal of Family Psychology, 19, 486-496. http://dx.doi.org/10.1037/0893-3200.19.4.486

Minnett, A., Clark, K., \& Wilson, G. (1994). Play behavior and communication between deaf and hard of hearing children and their hearing peers in an integrated preschool. American Annals of the Deaf, 139, 420-429. http://dx.doi.org/10.1353/aad.2012.0345

Moller, M. P. (2000). Early intervention and language development in children who are Deaf and Hard of Hearing. Pediatrics, 106, e43. http://dx.doi.org/ 10.1542/peds.106.3.e43

Most, T. (2007). Speech intelligibility, loneliness, and sense of coherence among deaf and hard-of-hearing children in individual inclusion and group inclusion. Journal of Deaf Studies and Deaf Education, 12, 495-503. http://dx.doi.org/10.1093/deafed/enm015

Nunes, T., Pretzlik, U., \& Olson, J. (2001). Deaf children's social relationships in mainstream schools. Deafness and Education International, 3, 123-136. http://dx.doi.org/10.1002/dei.106

Peterson, C. C., \& Siegal, M. (2000). Insights into theory of mind from deafness and autism. Mind and Language, 15, 123-145. http://dx.doi.org/10.1111/1468-0017.00126

Punch, R., \& Hyde, M. (2011). Social participation of children and adolescents with cochlear Implants: A qualitative analysis of parent, teacher, and child interviews. Journal of Deaf Studies and Deaf Education, 16(4), 474-493. http://dx.doi.org/10.1093/deafed/enr001

Rieffe, C., \& Terwogt, M. M. (2006). Anger communication in deaf children. Cognition and Emotion, 20, 1261-1273. http://dx.doi.org/10.1080/02699930500513502 
Rodriguez, M. S., \& Lana, E. T. (1996). Dyadic interactions between deaf children and their communication partners. American Annals of the Deaf, 141, 245-251. http://dx.doi.org/10.1353/aad.2012.0275

Rubin, K. H., Bukowski, W. M., Parker, J. G. (2006). Peer Interactions, Relationships, and Groups. In W. Damon., N. Eisenberg., \& R. M. Lerner (Eds.), Handbook of Child Psychology: Social, Emotion, and Personality Development (pp. 571-645). Hoboken: John Wiley \& Sons. Inc.

Sandgren, O., Ibbertsson, T., Andersson, R., Hansson, K., \& Sahlen, B. (2011). 'You sometimes get more than you ask for': responses in referential communication between children and adolescents with cochlear implant and hearing peers. International Journal of Language \&Communication Disorders, 4, 375-385. http://dx.doi.org/ 10.3109/13682822.2010.507617

Schorr, E. A. (2006). Early Cochlear implant experience and emotional functioning during childhood: Loneliness in middle and late childhood. The Volta Review, 106, 365-337. Retrieved from http://web.ebscohost.com.proxy-ub.rug.nl/ehost/pdfviewer/pdfviewer?vid=3\&sid=1b4d3279-abb1-4833-83 aa-b84dc8bbed6b\%40sessionmgr110\&hid=113

Stinson, M. S., \& Kluwin, T. (1996). Social orientations toward deaf and hearing peers among deaf adolescents in local public high schools. In P. C. Higgins, \& J. E. Nash (Eds.), Understanding deafness socially (pp. 113-134). Springfield, IL: Charles C. Thomas.

Stinson, M. S., \& Whitmire, K. (1992). Children' views of their social relationships. In T. N. Kluwin, D. F. Moores, \& M. G. Gaustad (Eds.), Towards effective public school programs for deaf children: Context process and outcomes (pp. 149-174). New York: Teachers College Press.

Suarez, M. (2000). Promoting social competence in deaf students: The effect of an intervention program. Journal of Deaf Studies and Deaf Education, 4, 323-336. http://dx.doi.org/10.1093/deafed/5.4.323

Vandell, D. L., \& George, L. (1981). Social interaction in hearing and deaf preschoolers: Successes and failures in initiations. Child Development, 52, 627-635. http://dx.doi.org/10.1111/1467-8624.ep8860512

Wray, D., Fleser, C., \& Vaccaro., V. (1997). Classroom performance of children who are deaf for hard of hearing and who learned spoken language through the auditory-verbal approach: An evaluation of treatment efficacy. The Volta Review, 99, 107-119. Retrieved from http://web.ebscohost.com.proxy-ub.rug.nl/ehost/detail?vid=3\&sid=e2547f7b-672b-43d6-b51a-3a6d979e4d 24\%40sessionmgr104\&hid=113\&bdata=JnNpdGU9ZWhvc3QtbGl2ZSZzY29wZT1zaXRl\#db=psyh\&AN= 2001-01322-003

Weisel, A., Most, T., \& Efron, C. (2005). Initiations of social interactions by young hearing impaired preschoolers. Journal of Deaf Studies and Deaf Education, 10, 161-170. http://dx.doi.org/10.1093/deafed/eni016

WHO. (1991). Report of the informal working group on prevention of deafness and hearing Impairment programme planning. Geneva: World Health Organization. Retrieved from http://whqlibdoc.who.int/hq/1991/WHO_PDH_91.1.pdf

Zins, J. E., Weissberg, R. P., Wang, M. C., \& Walberg, H. J. (2004). Building academic success on social and emotional learning: What does the research say? New York: Teachers College Press.

\section{Copyrights}

Copyright for this article is retained by the author(s), with first publication rights granted to the journal.

This is an open-access article distributed under the terms and conditions of the Creative Commons Attribution license (http://creativecommons.org/licenses/by/3.0/). 